\title{
37 Years an Academic Scientist
}

\section{Christopher M. Sorensen, Courtelyou-Rust University Distinguished Professor, University Distinguished Teaching Scholar, Kansas State University}

$\mathrm{T}$ The basis for this brief paper is my 20 minute presentation at the Merrill Advanced Studies Center conference "Planning for Future Research in Public Universities in Uncertain Times" that was held July 16 - 18, 2014 in Nebraska City, Nebraska. These are uncertain times; indeed, aren't they all? As Heraclitus observed "one does not step into the same river twice." Change is time itself, and as such, we should embrace it; we should use it. How can we use these uncertain times to our advantage? I think that by being more prepared for change, we gain an advantage over our rivals. To be prepared for change we must learn from the past and plan accordingly for the future. That is my purpose here.

I began my career as an academic scientist in August 1977, 37 years ago. I began as a tenure track assistant professor of physics at Kansas State University. As a professor, one has two major missions, teaching and research. Added to these is a smaller service component. In this paper I will use my experience as an academic scientific researcher to gain a perspective of the state of academic research today and how we got to where we are.

The majority of my first grants were funded by the NSF. This is consistent with the fact that I trained to be a scientist, not an engineer or applied scientist. Looking further back, I trained to be a scientist because I grew up in the 50 's, only a few decades after the revolutions in physics, quantum mechanics and relativity theory. My junior-high mind clearly saw that scientists, driven by simple curiosity, could revolutionize not only our world view but lay the foundation of modern technological wonders as well.
Looking at summaries (abstracts) from those early grants one immediately sees the lack of Intellectual Merit and Broader Impacts categories now mandated by the NSF. One might say that back when I started my career, NSF only cared about intellectual merit, and it was assumed the reader was smart enough to find that in the abstract without a category. I guess they saw it like I saw it in the 50's, that is, good science was enough, the rest, broader impacts, would follow. Indeed, it was the National Science Foundation, wasn't it?

My most recent grant funded by NSF (2013) has the Intellectual Merit and Broader Impacts categories. Without these categories explicitly included, grants are returned without review (regardless of the scientific quality). Reading the summary reveals more differences. My early summaries only talked about the science and its implications for science. The most recent grant summary 
discusses global climate change (the research will study light scattering by aerosol particles), integrating research with teaching, a summer workshop for teen women, involvement of undergraduates in research, an upper level undergraduate course on light scattering, talks at high schools, mentorship of ACS Project SEED students, and writing of a monograph on light scattering. Whew! Tell me again, how many hours are there in a one in eight probability of funding is quite desperate. This problem is not limited to astronomers; it's endemic throughout the sciences. However, astronomers, like all scientists, I believe, are resilient, as indicated by their collective response to this dire situation. They submitted grants three times more often!

My own funding success rate tells a similar story. My NSF Fastlane site shows that I'm successful on about $15 \%$ of my

\section{The no's have it}

More astronomy proposals contribute to plunging success rates at NSF

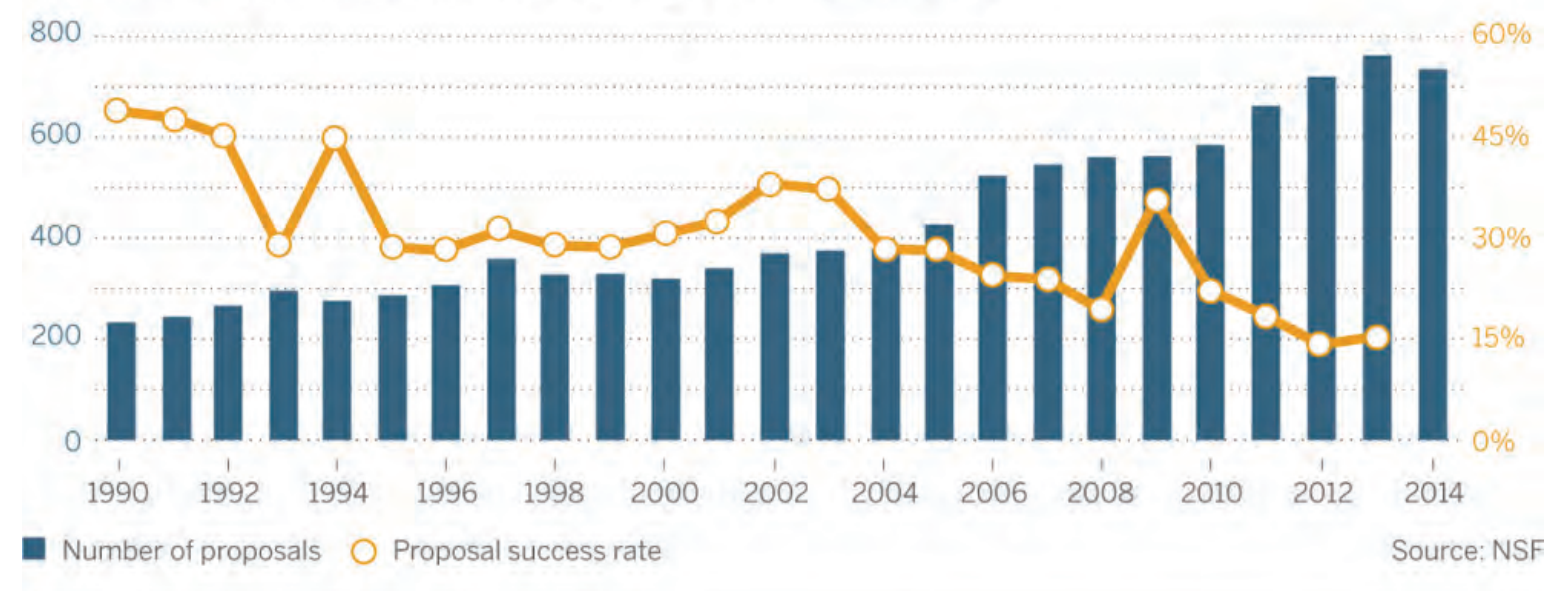

Figure 1. Funding success rate and number of proposals submitted for NSF astronomy programs since 1990. [1]

day? So the point is that in 1978 I proposed to do good science while in 2013 I proposed to do good science and a whole bunch of other stuff too.

A well-known change that has occurred through my years is the probability of getting a grant funded. As above, I will use NSF as an example. Figure 1 is from a recent article in Science [1]. It shows the funding success rate for astronomers over the past quarter century has steadily declined from $48 \%$ in 1990 to $15 \%$ in 2013 , a drop of over a factor of three. That is a drastic fall off and anyone would agree that a grant requests over the past few years. How did I respond? I wrote more grants.

It's good to have a solution in hand, writing more grants, but writing more grants takes time away from the reason why we write the grants, doing more science. I also think that preparing to do all the outreach and teaching activities gets in the way of the science. Half of my job (and my passion) is teaching and I really don't need NSF to insist I pay attention to it.

The universal decline in science funding leads to the irony that we all owe our prosperity and our health prospects 
to advances in the sciences. NIH Director Francis Collins stated in recent testimony to Congress, "Our nation has never witnessed a time of greater promise for advances in medicine." Yet NIH's budget for fiscal year 2014 (FY14) is 11.7\% below the FY04 peak [2]. I write this article at a desk top computer with orders of magnitude more power than the mainframe computer that I used for my first scientific researches as an undergraduate at the University of Nebraska in the late 60's; a computer that occupied a large room. We all know this but many of us don't seem to recognize that if this prosperity is to continue we must support the sciences as much as ever.

So what do we academic scientists do in this dire situation? How can our universities help us win the grants to keep our researches going?

Let me itemize things that are either necessary or would be very helpful for single or few investigator grants:

- Solid infrastructure is the foundation. I need a plethora of diagnostic equipment that are too expensive and require too much expertise to run and money to maintain by a single investigator. Things like electron microscopes, XPS and X-ray diffraction. It is the university's role to provide these devices, man them with expert operators and provide for their continued maintenance.

- The university should also have in place outreach connections across a wide range of venues such as K-12 schools, community colleges, minority institutions, civic groups, museums, etc.

- It would be very useful to have readers to read drafts of our grants and give advice. Readers who know the current trends and buzzwords, the ins and outs of the funding agencies.

Through my 37 years there has been an unmistakable trend for research to be performed in collaborations. I see this as part of a more general trend for group activities. For example, we now identify peer instruction as a viable teaching method and encourage our students to work on their homework in groups (So much for the rugged individual). The other undeniable trend is for interdisciplinary or multidisciplinary research. Funding agencies and others claim that modern problems are too complex for a single investigator or a single discipline (I guess we long for the good ol' days when problems were simple and straightforward). So, like it or not, we find ourselves aspiring to win big grants for lots of money involving many researchers. I have led a handful of such grant efforts and with those experiences, I can itemize things that are either necessary or would be very helpful for multi-investigator grants:

- A coordinator from the pre-awards office who knows all the ins and outs of organizing and constructing large multi-investigator grants. This person advises the group during grant construction, works alongside the PI, and perhaps more than anyone reads the RFP!

- A secretary for the PI during construction. The PI no doubt has his or her own research and teaching responsibilities that cannot be neglected.

- As for single investigator grants (and perhaps even more needed) outreach in place: K-12 schools, community colleges, minority institutions, civic groups, museums, etc. In addition, big grants typically stress diverse student 
recruitment and connections to minority institutions.

- Solid infrastructure is the foundation.

- A technical writer. The PI and CoPIs will write the science, the technical writer will make sure it is communicated very well.

- Readers who know the current trends. Perhaps people who have served on previous review panels. Much like all universities have congressional liaisons they should also have funding agency liaisons. These are not lobbyists. Rather they are liaisons in the truest sense: people who foment mutually beneficial interactions by knowing the needs of both parties very well.

- Institutional Assessment ability. Very often major grants propose novel programs to advance science, teaching or outreach. Such programs need assessment to determine their efficacy.

- Administration for big grants. Once the grant is awarded (oh happy day!) it must be managed. The scientists want to be in the lab doing the science, I assume, so managers need to be found to run the non-science part of the grant.

- Last but not least, a record of collaborative previous work.

Although I list it last, a record of collaborative previous work is the first requirement to improve the chance of success. How is such a record acquired? Certainly research collaborations are born, one way or another, all the time. Sometimes such collaborations fit the request for proposals (RFPs) and those collaborations can adapt to the RFP and submit a viable proposal. Most of the time, however, the fit is imperfect and adjustments need to be made in research direction. Even more often, with major RFPs, the collaborative group is smaller than the scope of the RFP. This leads to the collaborative group "beating the bushes" to find other researchers who might add to and complete the team to fit the RFP scope. Beating the bushes is much easier if the university has a detailed database of the research interests and capabilities of the faculty. And such a database warrants a bullet.

- A detailed data base of the research interests and capabilities of the faculty.

Collaborations might not exist to satisfy the objectives of a particular RFP, yet the objectives could well align to partial extents with a variety of faculty. Thus it would seem wise if the university could anticipate RFPs. This can be done by looking at previous calls for proposals and the programs that stimulated them. For example, NSF has for years funded Materials Research Science and Engineering Centers (MRSEC). It would be wise to plan ahead of the next RFP by assembling a group of researchers who might contribute to a MRSEC. Led by senior faculty a research agenda could be outlined. Then a crucial step would be to gain a significant record of collaborative previous work. Such work needs to be funded and the university should fund it with seed moneys. These moneys would pay for students, for the entire degree cycle, materials and supplies and some travel. Such a seed grant is an essential investment a university must make if it is to compete effectively for major grants. Thus I add another bullet.

- Seed grants to gain a record of collaborative previous work must be supplied by the university.

Another use of seed money is to prepare a failed but worthy major grant re- 
quest for the next opportunity for funding. We all know that to win grants one must often try and try again. Use the reviewer's criticisms, address them with more research to support a hypothesis or develop a technique. And the university should make the investment to do this.

\section{Who should fund our work?}

A growing funding source is the private sector. Corporate entities based on technology need research to create new and competitive products. However, there are many cultural differences between the corporate and academic worlds that need to be overcome or dealt with. These differences are not insurmountable if a philosophy of mutual benefit is kept in mind. This is a huge and detailed topic that I know only a little about so I will stop here.

I think universities should plan to support their own research by proper management of the intellectual property (IP) their faculty produces. This appears to be a growing realization but still awakening. Younger professors are much more aware of IP than I was 37 years ago, and so am I! We need to ensure that production of IP is seen as valuable to the academic world and an indication of scholarly success when evaluating faculty for tenure and promotion. We also need to have active research offices that continue to encourage the production of IP as well as publications from the faculty. These research offices also need to develop strategies for help faculty produce more IP and how to effective license it once produced. Most generally, IP has to become part of the culture of the university.

A novel idea is to use our teaching abilities to create capital. Yes, I know, that's been called tuition, but I mean something more. We can produce "classes" that would have general appeal to the public. These could be Nova-like productions on science, or interesting presentations in the arts or humanities. These presentations, either singly or as a series (a class), would be available on line for a price. This is much different than the many MOOC style classes available for free on the internet. We would be selling intellectual entertainment, not knowledge nor degrees.

From the societal or governmental point of view, I propose the future should heed the past. Most academics know very well the prescience of Vannevar Bush who wrote "Science the Endless Frontier", a letter to the president [3] that laid the foundation for the NSF and set the tone for other government funding agencies. Bush foresaw that curiosity based science was both part of human nature and the necessary foundation for technical advances. Academic science has thrived for nearly 70 years as a result. Although funding from such agencies is getting more difficult, as described above, the agencies are not going away yet. Hence the federal government will still be a significant source of academic research funding, especially following the advice above.

We must also recognize we are not as powerless in influencing the federal budget and the public perception of academic research as some of us seem to think. In a recent editorial in Science [2] John Edward Porter, a former U.S. congressman and chair of Research!America argued that "we must convince the public and our representatives that cutting research is not a pathway to deficit reduction; it is a pathway to increased health 
threats, lost lives, and economic insecurity". And yet, Porter points out "there has been little outreach by scientists to the public to help them understand how science contributes to better health, job creation, and global competitiveness." Furthermore he writes "Scientists remain largely invisible to the public"

You would think professional teachers (which we academics are the other $100 \%$ of our time) would be terrific at communicating these important messages to the public. Well maybe we are, but we rarely try. Let's try.

We can try, Porter suggests, by writing op-eds and letters to the editor of local newspapers about the latest scientific breakthroughs and their implications for society. We can volunteer to speak at local organizations, chambers of commerce, junior high and high schools about our work or the latest discoveries. We could offer to be a scientific advisor for candidates or create and serve on science advisory committees.

Finally, I believe we should not forget that we have the opportunity to profoundly influence the future every class day by teaching the value of science to our students. By letting them know that we not only teach but do research as well. By being good and reasonable people to win their respect and thus ensure our arguments gain efficacy. What we do in the classroom might not have an effect overnight, but it will certainly change the future.

\section{References}

[1] J. Mervis, Just one proposal per year, please, NSF tells astronomers, Science 344, 1328, 20 June 2014.

[2] J. E. Porter, Science 344, 1207, 13 June 2014.

[3] V. Bush, Science the Endless Frontier, a July 1945 report to the president, United States Government Printing Office, Washington: 1945. 